\title{
The Method for Product Design Selection with Incomplete Linguistic Weight Information Based on Quality Function Deployment in a Fuzzy Environment
}

\author{
Ming Li \\ School of Business Administration, China University of Petroleum, Beijing 102249, China \\ Correspondence should be addressed to Ming Li; limingzyq@gmail.com
}

Received 24 January 2013; Revised 24 March 2013; Accepted 24 March 2013

Academic Editor: Jung-Fa Tsai

Copyright (C) 2013 Ming Li. This is an open access article distributed under the Creative Commons Attribution License, which permits unrestricted use, distribution, and reproduction in any medium, provided the original work is properly cited.

\begin{abstract}
The selection of a design for the given product is a critical problem in product design development. Focuses of the designers and customers on the design are not identical. In order to bridge the gap and provide a more relaxing way to select the design, a new method based on quality function deployment (QFD) is proposed. In such a method, customers are required to give their linguistic preferences on the design with respect to the customer requirements (CRs). In the rating of the weight of CRs, they are allowed to provide incomplete linguistic weight information and the objective optimization model is proposed to derive the exact linguistic weight information. Designers are required to rate the correlation between design requirements (DRs) and the relationship between the CRs and DRs to construct the house of quality. Opinions given by the customers are translated into the opinions with respect to the DRs based on the QFD. Afterwards, the priorities of the designs and design requirements are determined. The assessment results not only show the contribution of each design requirement to the customer satisfaction but also show the advantages and disadvantages of each design from the designers' perspective clearly and directly. An example is provided to validate the applicability of the proposed method.
\end{abstract}

\section{Introduction}

The selection of the particular design for a given product is perhaps the most critical problem in product design development [1-3]. Designs are often evaluated from many aspects by groups of decision makers. Since the product is customer oriented, the opinions given by customers greatly impact the eventual success or failure of a product in the market [4-6]. The criteria which are constructed from the designer's perspective reflect the characteristic of the design, but the customers are not familiar with the criteria and they cannot fully express their preferences. On the contrary, the criteria which are constructed from the customer's perspective facilities the expression of customer requirements, but the evaluation results cannot reflect the advantages and disadvantages of the design clearly and directly, which is important for the improvement of the design. Therefore, methods are needed to take the advantages of the evaluations with respect to the two kinds of criteria.
Quality function deployment (QFD) provides the way to connect the customers' preferences and designers' preferences. It is a useful tool that deploys the voice of customer into searching for best solutions for the design and development of products [7]. QFD translates the customer requirements (CRs) into design requirements (DRs) that are considered in product design. Each translation can be represented graphically in a matrix configuration generally known as the house of quality (HoQ) $[8,9]$, as shown in Figure 1. HoQ is composed of six parts: Area A represents customer requirements (CRs), which are the criteria constructed from the customers' perspective. Area B represents the importance level of CRs. Area C represents design requirements (DRs), which are the criteria constructed from the designers' perspective. Area D represents the relationship of CRs and DRs. Area E indicates how DRs affect each other. Area F represents the priority of DRs.

In the selection of designs, customers are required to rate the alternatives and give the weight information of 


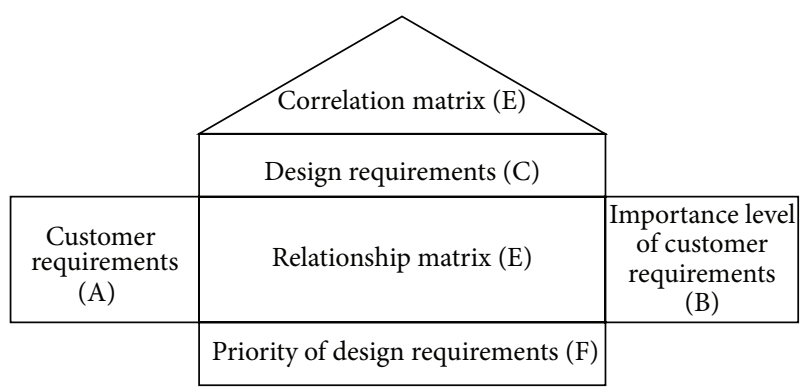

FIGURe 1: House of quality (HOQ).

CRs. In the construction of $\mathrm{HoQ}$, designers are required to give their opinions about the correlations between DRs and relationships between CRs and DRs. The data available in the early stage of new product design is often limited and inaccurate [10-12]. Decisions are often have to be made with vague, imprecise, and uncertain information. It is more suitable for decision makers to express their preferences by means of linguistic terms instead of numerical ones considering the uncertain knowledge they have about the problem $[13,14]$.

Although the QFD has been extended in a fuzzy environment [12, 15], it fails to solve the selection problem with incomplete linguistic weight information of CRs. In this paper, a new method for product design selection with incomplete linguistic weight information of CRs based on QFD in a fuzzy environment is developed. The remainder of this paper is set out as follows. In the next section, we introduce some basic concepts of the fuzzy linguistic model. In the third section, we develop a practical method based on QFD for product design selection with incomplete linguistic weight information of CRs. In Section 4, we give an illustrative example to illustrate the availability of the proposed model. In the final section, we conclude the paper.

\section{Preliminaries}

2.1. Fuzzy Linguistic Model. Decisions are always made under uncertain frameworks in real world. Probabilistic models have been provided to manage uncertainty in decision problems. However, most uncertainty has a nonprobabilistic nature. It is more practical for decision makers to give their opinions by terms close to human beings' cognitive model $[13,16]$. Fuzzy linguistic approach based on the fuzzy set theory has been used to model such an uncertainty by means of linguistic variables [14]. The use of linguistic information needs the operation of linguistic variables. Computing with words (CWW) is the methodology for decision making, in which the information is described by words $[17,18]$ or sentences [19] in natural language. It imitates human cognitive processes to improve solving processes of problems dealing with uncertainty.

There are two computational models developed to perform linguistic computations based on the fuzzy linguistic approach $[20,21]$. The first one is the linguistic computing model based on membership functions [20]. The model carries out the computations with linguistic terms by operating with their membership functions. The results obtained by the fuzzy linguistic operators are fuzzy numbers that usually do not match with any linguistic term in the initial term set. The second one is symbolic linguistic computing model based on ordinal scales $[21,22]$. It uses the ordered structure of the linguistic term set to accomplish symbolic computations. Because of the simplicity and high interpretability, symbolic models have been widely used and extended. For example, Herrera et al. [23] present a fuzzy linguistic method dealing with unbalanced linguistic term sets to evaluate students' knowledge. Herrera and Herrera-Viedma [24] study the steps to follow in linguistic decision analysis to select the investment options. Mata et al. [25] proposed an adaptive consensus support system model to choose the best brand of wine. These models deal with the linguistic information effectively, but there exists a drawback of loss of information [17]. The calculation results of these models usually do not exactly match any of the initial linguistic terms and the approximation process must be developed to express the result in the initial expression domain. As a result, the consequent loss of information and hence the lack of precision are produced.

Many linguistic computing models are proposed to improve the accuracy and understandability in linguistic decision making, such as the 2-tuple linguistic model [26], the virtual linguistic model [27], and the proportional 2-tuple linguistic model [28]. In these models, the 2-tuple linguistic model is the most adequate linguistic computing model to deal with linguistic information in decision problems [17]. It keeps a syntax and fuzzy semantics. In the model, the results match the initial linguistic terms in its representation. The approximation process is not needed, and as a result, there is no loss of information. Thus, it can provide more accurate and, understandable results for human beings $[26,29,30]$. The 2-tuple linguistic model has been used in many areas such as hotel service quality evaluation [31], health-related websites quality evaluation [32], and quality evaluation of websites that store XML documents [33].

In the following, we briefly review the 2-tuple fuzzy linguistic representation model $[26,29]$.

The 2-tuple linguistic representation model is based on the concept of symbolic translation. It is used for representing the linguistic evaluation information by means of a 2-tuple that is composed of a linguistic term and a number. It can be denoted as $\left(s_{i}, \alpha\right)$ where $s_{i}$ represents the linguistic label of the predefined linguistic term set $S$, and $\alpha$ indicates the distance to the central value of the $i$ th linguistic term. For example, a set of seven terms $S$ could be given as follows:

$$
\begin{aligned}
S=\left\{S_{0}\right. & =\text { Definitely Low }(\mathrm{DL}), \\
S_{1} & =\operatorname{Very} \operatorname{Low}(\mathrm{VL}), \\
S_{2} & =\operatorname{Low}(\mathrm{L}), S_{3}=\operatorname{Middle}(\mathrm{M}), \\
S_{4} & =\operatorname{High}(\mathrm{H}), S_{5}=\operatorname{Very} \operatorname{High}(\mathrm{VH}), \\
S_{6} & =\operatorname{Definitely} \operatorname{High}(\mathrm{DH})\} .
\end{aligned}
$$


Definition 1. Let $s_{i} \in S$ be a linguistic label. Then the function $\Delta$ used to obtain the corresponding 2-tuple linguistic information of $s_{i}$ is defined as

$$
\begin{gathered}
\Delta: S \longrightarrow S \times[-0.5,0.5), \\
\Delta\left(s_{i}\right)=\left(s_{i}, 0\right), \quad s_{i} \in S .
\end{gathered}
$$

Definition 2. Let $S=\left\{S_{0}, S_{1}, \ldots, S_{T}\right\}$ be a linguistic term set; let $\beta \in[0, T]$ be a number value representing the aggregation result of linguistic symbolic. Then the symbolic translation process is applied to translate $\beta$ into a 2 -tuple linguistic variable. The generalized translation function $(\Delta)$ can be represented as

$$
\begin{gathered}
\Delta:[0, T] \longrightarrow S \times[-0.5,0.5), \\
\Delta(\beta)=\left(S_{i}, \alpha\right)= \begin{cases}S_{i}, & i=\operatorname{Round}(\beta) \\
\alpha=\beta-i, & \alpha \in[-0.5,0.5),\end{cases}
\end{gathered}
$$

where $\operatorname{Round}(\cdot)$ is the usual round operation, $s_{i}$ has the closest index label to $\beta$, and $\alpha$ is the value of the symbolic translation.

Definition 3. The 2-tuple linguistic variable can be converted into an equivalent numerical value $\beta(\beta \in[0, T])$ by the following formula:

$$
\Delta^{-1}\left(S_{i}, \alpha\right)=i+\alpha=\beta,
$$

where $\Delta^{-1}\left(S_{i}, \alpha\right)$ signifies a reverse equation for converting the 2-tuple linguistic variable into a crisp value, $\beta$ is a number value representing the aggregation result of linguistic symbolic, and $\alpha$ is a numerical value which represents the symbolic translation.

Definition 4 (Negative Operator). Consider

$$
\operatorname{Neg}\left(S_{i}, \alpha\right)=\Delta\left(T-\left(\Delta^{-1}\left(S_{i}, \alpha\right)\right)\right) .
$$

Definition 5. Let $x=\left\{\left(r_{1}, \alpha_{1}\right), \ldots,\left(r_{n}, \alpha_{n}\right)\right\}$ be a 2-tuple linguistic variable set; their arithmetic mean $\bar{x}$ can be calculated as

$$
\bar{x}=\Delta\left[\frac{1}{n} \sum_{i=1}^{n} \Delta^{-1}\left(r_{i}, \alpha_{i}\right)\right]=\Delta\left(\frac{1}{n} \sum_{i=1}^{n} \beta_{i}\right) .
$$

Definition 6. When $x=\left\{\left(r_{1}, \alpha_{1}\right), \ldots,\left(r_{n}, \alpha_{n}\right)\right\}$ is a 2-tuple linguistic variable set and $W=\left\{w_{1}, \ldots, w_{n}\right\}$ is the weight set of linguistic terms, the 2-tuple linguistic weighted average $\bar{x}^{w}$ can be computed as

$$
\bar{x}^{w}=\Delta\left[\frac{\sum_{i=1}^{n} \Delta^{-1}\left(r_{i}, \alpha_{i}\right) \times w_{i}}{\sum_{i=1}^{n} w_{i}}\right]=\Delta\left(\frac{\sum_{i=1}^{n} \beta_{i} \times w_{i}}{\sum_{i=1}^{n} w_{i}}\right) .
$$

Definition 7. Let $x=\left\{\left(r_{1}, \alpha_{1}\right), \ldots,\left(r_{n}, \alpha_{n}\right)\right\}$ be a 2-tuple linguistic variable set and $W=\left\{\left(w_{1}, \alpha_{1}^{w}\right), \ldots,\left(w_{n}, \alpha_{n}^{w}\right)\right\}$ their linguistic 2-tuple associated weights. This linguistic weighted average operator can be computed as

$$
\bar{x}_{l}^{w}=\Delta\left(\frac{\sum_{i=1}^{n}\left[\Delta^{-1}\left(r_{i}, \alpha_{i}\right) \times \Delta^{-1}\left(w_{i}, \alpha_{i}^{w}\right)\right]}{\sum_{i=1}^{n} \Delta^{-1}\left(w_{i}, \alpha_{i}^{w}\right)}\right) .
$$

Definition 8. If $\left(S_{i}, \alpha_{i}\right)$ and $\left(S_{j}, \alpha_{j}\right)$ are two 2-tuple linguistic variables, with each one representing a counting of information as follows:

(1) when $i>j,\left(S_{i}, \alpha_{i}\right)$ is better than $\left(S_{j}, \alpha_{j}\right)$;

(2) if $i=j$ and $\alpha_{i}>\alpha_{j}$, then $\left(S_{i}, \alpha_{i}\right)$ is better than $\left(S_{j}, \alpha_{j}\right)$;

(3) if $i=j$ and $\alpha_{i}<\alpha_{j}$, then $\left(S_{i}, \alpha_{i}\right)$ is worse than $\left(S_{j}, \alpha_{j}\right)$;

(4) if $i=j$ and $\alpha_{i}=\alpha_{j}$, then $\left(S_{i}, \alpha_{i}\right)$ is equal to $\left(S_{j}, \alpha_{j}\right)$.

2.2. Incomplete Information. In decision making, decision makers need to give their assessment information about the alternatives. Complete preferences are always difficult to be given. For example, a decision maker cannot provide exact estimations of criteria weights or he/she is not willing or able to specify the preferences in detail. This may be due to time pressure and lack of data, limited attention, and information processing capabilities, or because many of the attributes are intangible or nonmonetary because they reflect social and environmental impacts [34-37]. In such situations, decision makers are forced to provide incomplete information. Therefore, tools are needed to aid the experts in dealing with this lack of knowledge in their opinions.

As usual, there are always two types of incomplete information.

The first type is the incomplete preference relation. Incomplete fuzzy preference relation means a fuzzy preference relation with some of its values missing or unknown $[36,37]$. It often exists in the decision making process when decision makers are not always able to provide preference degrees between every pair of possible alternatives. Methods have been proposed to resolve the problem. For example, Herrera-Viedma et al. [38] presented a consensus model for decision making problems with incomplete fuzzy preference relations. Herrera-Viedma et al. [39] proposed an iterative procedure to estimate the missing information in incomplete fuzzy preference relation. The method has also been used in recommender system in university digital libraries [36]. Alonso et al. [37] proposed a procedure to estimate missing preference values of incomplete fuzzy linguistic preference relations using a two-tuple fuzzy linguistic approach.

The second type is the incomplete weight information. In the study, we focus on this type of incomplete information. Incomplete weight information means the weight of the criteria is partially known $[34,35]$. The weight information can be partially given in the form of linear inequalities such as rankings and interval descriptions. Examples of incomplete information on criteria weights are given by the following forms $[34,35]$ :

Form 1. A weak ranking: $\left\{w_{i} \geq w_{j}\right\}$;

Form 2. A strict ranking: $\left\{w_{i}-w_{j} \geq \alpha_{i}\right\}$;

Form 3. A ranking with multiples: $\left\{w_{i} \geq \alpha_{i} w_{j}\right\}$;

Form 4. An interval form: $\left\{\alpha_{i} \leq w_{i} \leq \alpha_{i}+\varepsilon_{i}\right\}$;

Form 5. A ranking of differences: $\left\{w_{i}-w_{j} \geq w_{l}-\right.$ $\left.w_{m}\right\}$, for $j \neq l \neq m$,

where, $w_{i}, w_{j}, w_{l}$, and $w_{m}$ are the weights of the criteria, $\alpha_{i}$ and $\varepsilon_{i}$ are the constants. The difficulty in taking the information 
of Forms 2-4 is to precisely define their constants. Form 5 is a ranking of differences of adjacent parameters obtained by ranking between two parameters, which can be subsequently constructed based on Form 1.

The incomplete weight information in which the constants and weights are in the form of linguistic terms is named as incomplete linguistic weight information. It facilitates the expression of preferences and makes the weights more understandable.

The main method to resolve the problem of incomplete weight information by the calculation of the exact weight information is linear programming technologies [40]. Many multiple criteria decision making methods have been extended with the incomplete weight information [41-45]. They all require the constants to be defined by precise numbers and the obtained weights are also precise numbers. However, few researches are conducted on the incomplete linguistic weight information.

\section{The Method for Product Design Selection with Incomplete Linguistic Weight Information of CRs Based on QFD in a Fuzzy Environment}

In new product design especially in the early stage, the data available is often limited and inaccurate [10-12]. Decisions have to be made with vague, imprecise, and uncertain information. It is hard to get crisp numbers. The opinions given by the decision makers have great influence on the accuracy of decision making. Since linguistic terms imitate human cognitive model and are understandable, decision makers can express their opinions more accurately. Therefore, the linguistic decision making methods are more fit than the crisp numerical methods in the product design selection.

Let $A=\left\{A_{1}, A_{2}, \ldots, A_{m}\right\}$ be a discrete set of alternatives, $\mathrm{CR}=\left\{\mathrm{CR}_{1}, \mathrm{CR}_{2}, \ldots, \mathrm{CR}_{p}\right\}$ the set of CRs, $\mathrm{DR}=\left\{\mathrm{DR}_{1}\right.$, $\left.\mathrm{DR}_{2}, \ldots, \mathrm{DR}_{q}\right\}$ the set of DRs, $D_{c}=\left\{D_{1}^{c}, D_{2}^{c}, \ldots, D_{t}^{c}\right\}$ and $D_{d}=\left\{D_{1}^{d}, D_{2}^{d}, \ldots, D_{v}^{d}\right\}$ the sets of customers and designers respectively, $u=\left\{u_{1}, u_{2}, \ldots, u_{q}\right\}$ be the linguistic weight vector of DRs, and $w=\left\{w_{1}, w_{2}, \ldots, w_{p}\right\}$ the linguistic weight vector of CRs, where $w_{j}=\left(w_{j}^{\prime}, \tau_{j}\right)$ and $u_{j}=\left(u_{j}^{\prime}, \rho_{j}\right)$ are represented by the 2-tuple linguistic model, $w_{j}^{\prime} \in S, u_{j}^{\prime} \in S$. $H$ is a set of the known weight information, which can be constructed by the following forms $[34,35,40,46]$, for $j \neq i$ :

Form 1. A weak ranking: $w_{i} \geq w_{j}$;

Form 2. A ranking of differences: $w_{i}-w_{j} \geq w_{k}-w_{l}$, for $j \neq l \neq k$;

Form 3. A strict ranking: $w_{i}-w_{j} \geq \beta_{i j}^{k}, \beta_{i j}^{k} \in S$;

Form 4. An interval form: $\delta_{i}^{k} \leq w_{i} \leq \gamma_{i}^{k}, \delta_{i}^{k} \leq$ $\gamma_{i}^{k}, \delta_{i}^{k}, \gamma_{i}^{k} \in S$.

Suppose $\mathrm{RL}^{k}=\left(r l_{i j}^{k}\right)_{p \times q}$ is the linguistic decision making matrix of relationship between $\mathrm{CR}_{i}$ and $\mathrm{DR}_{j}, \mathrm{CL}^{k}=\left(\mathrm{cl}_{i j}^{k}\right)_{q \times q}$ the linguistic decision making matrix of the correlation between $\mathrm{DR}_{i}$ and $\mathrm{DR}_{j}$, and $R^{k}=\left(r_{i j}^{k}\right)_{m \times p}$ the linguistic decision making matrix of the rating of alternative $A_{i}$ with respect to $\mathrm{CR}_{j}$.

The steps of the proposed method are as follows.

Step 1. Calculate the collective rating of the alternatives with respect to CRs.

Step 1.1. Transform the linguistic decision matrix $R_{k}=$ $\left(r_{i j}^{k}\right)_{m \times p}$ into 2-tuple linguistic decision matrix $R_{k}=$ $\left(r_{i j}^{k}, 0\right)_{m \times p}$.

Step 1.2. Utilize the decision information given in matrix $R_{k}$ to derive the collective overall 2-tuple linguistic decision matrix $R=\left(r_{i j}, \alpha_{i j}\right)_{m \times p}$,

$$
\begin{gathered}
\left(r_{i j}, \alpha_{i j}\right)=\Delta\left(\frac{1}{t} \sum_{k=1}^{t} \Delta^{-1}\left(r_{i j}^{k}, 0\right)\right), \\
i=1,2, \ldots, m, \quad j=1,2, \ldots, p .
\end{gathered}
$$

Step 2. Calculate the collective incomplete weight information of CRs.

Form 1 and Form 2: for the same CRs, if there are no conflicts in $H$, then all the weight information will be preserved. On the contrary, if there are conflicts in $H$, majority voting $[47,48]$ is employed to eliminate conflicts, that is, only the weight information that obtains the most votes is preserved.

Forms 3 and 4: aggregate the weight information of CRs into the group assessment information.

The weight information of $w_{i}-w_{j}$ in Form 3 is aggregated as follows:

$$
w_{i}-w_{j} \geq \Delta\left(\frac{1}{f} \sum_{k=1}^{f}\left(\beta_{i j}^{k}, 0\right)\right),
$$

where $f$ is the number of customers that give weight information about $\mathrm{CR}_{i}$ and $\mathrm{CR}_{j}$ in Form 3 . follows:

The weight information of $w_{i}$ in Form 4 is aggregated as

$$
\Delta\left(\frac{1}{f} \sum_{k=1}^{z}\left(\delta_{i}^{k}, 0\right)\right) \leq w_{i} \leq \Delta\left(\frac{1}{f} \sum_{k=1}^{z}\left(\gamma_{i}^{k}, 0\right)\right),
$$

where $z$ is the number of customers that give weight information about $\mathrm{CR}_{i}$ in Form 4.

Step 3. Determine the weight of the CRs.

The weighted rating $\left(r_{i}^{w}, \alpha_{i}^{w}\right)$ of the alternatives $A_{i}$ is calculated based on the rating with respect to CRs and weight of CRs:

$$
\left(r_{i}^{w}, \alpha_{i}^{w}\right)=\Delta\left(\sum_{k=1}^{p}\left(\Delta^{-1}\left(r_{i k}, \alpha_{i k}\right) \times \Delta^{-1}\left(w_{k}^{\prime}, \tau_{k}\right)\right)\right) .
$$

Since the information about weights of CRs is partially known, based on the principles that the alternatives that 
obtain the highest weighted rating are the best one, in order to obtain the $\left(r_{i}^{w}, \alpha_{i}^{w}\right)$, we establish the following single objective optimization model (M1):

$$
\max \left(w_{k}^{\prime}, \tau_{k}\right)=\Delta\left(\sum_{k=1}^{p}\left(\Delta^{-1}\left(r_{i k}, \alpha_{i k}\right) \times \Delta^{-1}\left(w_{k}^{\prime}, \tau_{k}\right)\right)\right),
$$

Subject to : $w \in \mathrm{H}, i=1,2, \ldots m$.

According to $\Delta^{-1}$ function, the objective optimization model (M1) can be transformed into the objective optimization model (M2):

$$
\max \Delta^{-1}\left(w_{k}^{\prime}, \tau_{k}\right)=\sum_{k=1}^{p}\left(\Delta^{-1}\left(r_{i k}, \alpha_{i k}\right) \times \Delta^{-1}\left(w_{k}^{\prime}, \tau_{k}\right)\right),
$$

Subject to : $w \in \mathrm{H}, \quad i=1,2, \ldots m$.

By solving the model M2, we obtain the optimal solution $w=\left\{w_{1}, w_{2}, \ldots, w_{p}\right\}$, which is the weight vector of CRs.

Step 4. Calculate the collective correlation between DRs.

Step 4.1. Transform linguistic decision matrix $\mathrm{CL}_{k}=\left(\mathrm{cl}_{i j}^{k}\right)_{q \times q}$ into 2-tuple linguistic decision matrix $\mathrm{CL}_{k}=\left(\mathrm{cl}_{i j}^{k}, 0\right)_{q \times q}$.

Step 4.2. Utilize the decision information given in matrix $\mathrm{CL}_{k}$ to derive the collective overall 2-tuple linguistic decision matrix $\mathrm{CL}=\left(\mathrm{cl}_{i j}, \epsilon_{i j}\right)_{q \times q}$ :

$$
\begin{gathered}
\left(\mathrm{cl}_{i j}, \epsilon_{i j}\right)=\Delta\left(\frac{1}{v} \sum_{k=1}^{v} \Delta^{-1}\left(\mathrm{cl}_{i j}^{k}, 0\right)\right), \\
i=1,2, \ldots, q, \quad j=1,2, \ldots, q .
\end{gathered}
$$

Step 5. Calculate the collective normalized relationship between CRs and DRs

Step 5.1. Transform the linguistic decision matrix $\mathrm{RL}_{k}=$ $\left(\mathrm{rl}_{i j}^{k}\right)_{p \times q}$ into 2-tuple linguistic decision matrix $\mathrm{RL}_{k}=$ $\left(\mathrm{rl}_{i j}^{k}, 0\right)_{p \times q}$.

Step 5.2. Utilize the decision information given in matrix $\mathrm{RL}_{k}$ to derive the collective overall 2-tuple linguistic decision matrix $\mathrm{RL}=\left(\mathrm{rl}_{i j}, \varepsilon_{i j}\right)_{p \times q}$ :

$$
\begin{gathered}
\left(\mathrm{rl}_{i j}, \varepsilon_{i j}\right)=\Delta\left(\frac{1}{v} \sum_{k=1}^{v} \Delta^{-1}\left(\mathrm{rl}_{i j}^{k}, 0\right)\right) \\
i=1,2, \ldots, p, \quad j=1,2, \ldots, q .
\end{gathered}
$$

Step 5.3. For obtaining relative relationship degrees of DRs with respect to CRs and dealing with the dependence among DRs, the normalized transform on the relationship values contained in the relationship matrix is used and expressed as [10-12]:

$$
\left(\mathrm{rl}_{i j}^{\prime}, \varepsilon_{i j}^{\prime}\right)=\frac{\sum_{h=1}^{q} \Delta^{-1}\left(\mathrm{rl}_{i h}, \varepsilon_{i h}\right) \times \Delta^{-1}\left(\mathrm{cl}_{h j}, \epsilon_{h j}\right)}{\sum_{j=1}^{q} \sum_{h=1}^{q} \Delta^{-1}\left(\mathrm{rl}_{i h}, \varepsilon_{i h}\right) \times \Delta^{-1}\left(\mathrm{cl}_{h j}, \epsilon_{h j}\right)} .
$$

Step 6. Calculate the rating of the alternatives with respect to the DRs.

The rating of the alternative $A_{i}$ with respect to the $\mathrm{DR}_{j}$ is obtained by the sum of multiplying the rating of the alternative $A_{i}$ with respect to each CR by the corresponding normalized relationship as

$$
\left(r_{i j}^{\prime}, \alpha_{i j}^{\prime}\right)=\Delta\left(\sum_{k=1}^{p} \Delta^{-1}\left(\mathrm{rl}_{k j}^{\prime}, \varepsilon_{k j}^{\prime}\right) \times \Delta^{-1}\left(r_{i k}, \alpha_{i k}\right)\right) .
$$

Step 7. Calculate the weight of the DRs.

The weight of the $\mathrm{DR}_{j}$ is obtained by the sum of multiplying the weight of CRs by the corresponding normalized relationship as

$$
\left(u_{j}^{\prime}, \rho_{j}\right)=\Delta\left(\sum_{k=1}^{p} \Delta^{-1}\left(\mathrm{rl}_{k j}^{\prime}, \varepsilon_{k j}^{\prime}\right) \times \Delta^{-1}\left(w_{k}^{\prime}, \tau_{k}\right)\right) .
$$

Step 8. Calculate the weighted rating of the alternatives with respect to the DRs.

The weighted rating of the alternatives $A_{i}$ is calculated based on the rating with respect to DRs and weight of DRs:

$$
\left(r_{i}^{\prime w}, \alpha_{i}^{\prime w}\right)=\Delta\left(\sum_{j=1}^{q}\left(\Delta^{-1}\left(r_{i j}^{\prime}, \alpha_{i j}^{\prime}\right) \times \Delta^{-1}\left(u_{j}^{\prime}, \rho_{j}\right)\right)\right) .
$$

Step 9. Rank the alternatives.

The alternatives are ranked in descending order of the weighed rating of the alternatives. With the proposed method, not only the best design is selected but also the advantage and disadvantage of each alternative can be identified directly. It facilitates the customer to express their preferences and make the evaluation results more understandable for designers. Moreover, the weights of DRs indicate the contribution of each design requirement to the customer satisfaction and more attention should be paid to the DRs with higher weights.

Note that if the designers only focus on which design is the best and lack of the interest in the reason to select the design, the ranking of the alternatives can be obtained by the sum of multiplying the weight of customer requirements by the corresponding rating of the alternatives after the third step.

\section{Case Studies}

In this section, the fully automatic washing machine development case is used to illustrate the proposed approach [49]. Our main focus is to evaluate the four designs which are denoted as $A_{1}, A_{2}$, and $A_{3}$ and $A_{4}$ and determine the best design. It is based on the assumption that the machine 
will be used by housewives in families. Decision makers including three customers which are denoted as $E_{1}, E_{2}$, and $E_{3}$ and three designers which are denoted as $E_{4}, E_{5}$, and $E_{6}$ are invited to give their preferences using the terms in the linguistic set $S$. From the analysis of the questionnaire results, five customer requirements are identified. These CRs include "thorough washing" $\left(\mathrm{CR}_{1}\right)$, "quiet washing" $\left(\mathrm{CR}_{2}\right)$, "thorough rinsing" $\left(\mathrm{CR}_{3}\right)$, "no damage to clothes" $\left(\mathrm{CR}_{4}\right)$, and "short washing time" $\left(\mathrm{CR}_{5}\right)$. The corresponding $\mathrm{DRs}$ include "washing quality" $\left(\mathrm{DR}_{1}\right)$, "noise level" $\left(\mathrm{DR}_{2}\right)$, "washing time" $\left(\mathrm{DR}_{3}\right)$, "rinsing quality" $\left(\mathrm{DR}_{4}\right)$, and "clothes damage rate" $\left(\mathrm{DR}_{5}\right)$.

Considering the values and weights of customer requirements, we see that it is hard to be given crisp numbers especially for the customers who are not specialized in product design. Moreover, since the linguistic terms are more understandable than crisp numbers, decision makers can give their opinions more easily and accurately.

The rating of the alternatives given by the three customers is shown in Table 1.

According to the judgment of the three customers, the information about the weights of CRs is partly known as follows:

$$
\begin{gathered}
\mathrm{H}^{1}=\left\{w_{1} \leq w_{4}, w_{5} \leq w_{1}, w_{3}-w_{2} \leq w_{4}-w_{5},\right. \\
\mathrm{H} \leq w_{1} \leq \mathrm{DH}, \mathrm{VL} \leq w_{2} \leq \mathrm{H}, \\
\mathrm{M} \leq w_{3} \leq \mathrm{VH}, \\
\left.\mathrm{H} \leq w_{4} \leq \mathrm{DH}, \mathrm{DL} \leq w_{5} \leq \mathrm{M}\right\}, \\
\mathrm{H}^{2}=\left\{w_{1} \leq w_{4}, w_{5} \leq w_{1}, \mathrm{H} \leq w_{1} \leq \mathrm{DH},\right. \\
\mathrm{DL} \leq w_{2} \leq \mathrm{M}, \mathrm{L} \leq w_{3} \leq \mathrm{VH}, \\
\left.\mathrm{VH} \leq w_{4} \leq \mathrm{DH}, \mathrm{DL} \leq w_{5} \leq \mathrm{M}\right\}, \\
\mathrm{H}^{3}=\left\{w_{1} \geq w_{4}, w_{3}-w_{2} \leq w_{4}-w_{5},\right. \\
\mathrm{M} \leq w_{1} \leq \mathrm{VH}, \mathrm{DL} \leq w_{2} \leq \mathrm{M}, \\
\mathrm{M} \leq w_{3} \leq \mathrm{DH}, \\
\left.\mathrm{L} \leq w_{4} \leq \mathrm{DH}, \mathrm{VL} \leq w_{5} \leq \mathrm{M}\right\} .
\end{gathered}
$$

The rating of the correlation between DRs given by the three designers is shown in Table 2.

The rating of the relationship between the CRs and DRs given by the three designers is shown in Table 3.

The steps to be taken are described as follows.

Step 1. Calculate the collective rating of the alternatives with respect to CRs.

Firstly, the linguistic decision matrixes in Table 1 are transformed into 2-tuple linguistic decision matrix and then the collective overall 2-tuple linguistic decision matrix can be derived, as shown in Table 4.

Step 2. Calculate the collective incomplete weight information of CRs.
Since there are conflicts about the relationship between $w_{1}$ and $w_{4}, w_{1} \leq w_{4}$ obtains two votes and $w_{1} \geq w_{4}$ obtains one votes; hence, the collective relationship is $w_{1} \leq w_{4}$.

The collective range of the weight can be derived by (11). For example, collective range of the weight $w_{1}$ can be calculated as

$$
\begin{aligned}
& \frac{\Delta^{-1}(\mathrm{H}, 0)+\Delta^{-1}(\mathrm{H}, 0)+\Delta^{-1}(\mathrm{M}, 0)}{3} \\
& \quad=\frac{4+4+3}{3}=(\mathrm{H},-0.33) \leq w_{1} \\
& \quad \leq \frac{\Delta^{-1}(\mathrm{DH}, 0)+\Delta^{-1}(\mathrm{DH}, 0)+\Delta^{-1}(\mathrm{VH}, 0)}{3} \\
& \quad=\frac{6+6+5}{3}=(\mathrm{DH},-0.33) .
\end{aligned}
$$

The collective incomplete weight information of CRs is as follows:

$$
\begin{gathered}
\mathrm{H}=\left\{w_{1} \leq w_{4}, w_{5} \leq w_{1}, w_{3}-w_{2} \leq w_{4}-w_{5},\right. \\
(\mathrm{H},-0.33) \leq w_{1} \leq(\mathrm{DH},-0.33), \\
(\mathrm{DL}, 0.33) \leq w_{2} \leq(\mathrm{M}, 0.33), \\
(\mathrm{M},-0.33) \leq w_{3} \leq(\mathrm{VH}, 0.33), \\
(\mathrm{H},-0.33) \leq w_{4} \leq(\mathrm{DH}, 0), \\
\left.(\mathrm{DL}, 0.33) \leq w_{5} \leq(\mathrm{M}, 0)\right\} .
\end{gathered}
$$

Step 3. Determine thSe weight of the CRs.

Firstly, we utilize the model (M2) to establish the following single objective optimization model to determine the weight:

$$
\begin{aligned}
& \min d(w)=\sum_{i=1}^{4} \Delta^{-1}\left(r_{i 1}, \alpha_{i 1}\right) \times w_{1} \\
&+\sum_{i=1}^{4} \Delta^{-1}\left(r_{i 2}, \alpha_{i 2}\right) \times w_{2} \\
&+\sum_{i=1}^{4} \Delta^{-1}\left(r_{i 3}, \alpha_{i 3}\right) \times w_{3} \\
&+\sum_{i=1}^{4} \Delta^{-1}\left(r_{i 4}, \alpha_{i 4}\right) \times w_{4} \\
&+\sum_{i=1}^{4} \Delta^{-1}\left(r_{i 5}, \alpha_{i 5}\right) \times w_{5} \\
&= 15.33 \times w_{1}+6.33 \times w_{2} \\
&+12.33 \times w_{3}+18.00 \times w_{4}+8.00 \times w_{5} .
\end{aligned}
$$

Suject to : $w \in \mathrm{H}$. 
TABLE 1: The rating of the alternatives given by the customers.

\begin{tabular}{cccccccccccccccc}
\hline & & & $E_{1}$ & & & & $E_{2}$ & & & & & \\
& $\mathrm{CR}_{1}$ & $\mathrm{CR}_{2}$ & $\mathrm{CR}_{3}$ & $\mathrm{CR}_{4}$ & $\mathrm{CR}_{5}$ & $\mathrm{CR}_{1}$ & $\mathrm{CR}_{2}$ & $\mathrm{CR}_{3}$ & $\mathrm{CR}_{4}$ & $\mathrm{CR}_{5}$ & $\mathrm{CR}_{1}$ & $\mathrm{CR}_{2}$ & $\mathrm{CR}_{3}$ & $\mathrm{CR}_{4}$ & $\mathrm{CR}_{5}$ \\
\hline$A_{1}$ & $\mathrm{DH}$ & $\mathrm{VL}$ & $\mathrm{H}$ & $\mathrm{DH}$ & $\mathrm{L}$ & $\mathrm{VH}$ & $\mathrm{M}$ & $\mathrm{H}$ & $\mathrm{H}$ & $\mathrm{L}$ & $\mathrm{H}$ & $\mathrm{VL}$ & $\mathrm{H}$ & $\mathrm{DH}$ & $\mathrm{L}$ \\
$A_{2}$ & $\mathrm{VH}$ & $\mathrm{L}$ & $\mathrm{M}$ & $\mathrm{DH}$ & $\mathrm{L}$ & $\mathrm{H}$ & $\mathrm{L}$ & $\mathrm{M}$ & $\mathrm{VH}$ & $\mathrm{M}$ & $\mathrm{M}$ & $\mathrm{L}$ & $\mathrm{H}$ & $\mathrm{VH}$ & $\mathrm{L}$ \\
$A_{3}$ & $\mathrm{M}$ & $\mathrm{DL}$ & $\mathrm{L}$ & $\mathrm{H}$ & $\mathrm{VL}$ & $\mathrm{M}$ & $\mathrm{M}$ & $\mathrm{H}$ & $\mathrm{H}$ & $\mathrm{M}$ & $\mathrm{M}$ & $\mathrm{DL}$ & $\mathrm{L}$ & $\mathrm{H}$ & $\mathrm{M}$ \\
$A_{4}$ & $\mathrm{M}$ & $\mathrm{VL}$ & $\mathrm{VL}$ & $\mathrm{M}$ & $\mathrm{VL}$ & $\mathrm{M}$ & $\mathrm{L}$ & $\mathrm{VH}$ & $\mathrm{VH}$ & $\mathrm{L}$ & $\mathrm{H}$ & $\mathrm{L}$ & $\mathrm{VL}$ & $\mathrm{L}$ & $\mathrm{VL}$ \\
\hline
\end{tabular}

TABLE 2: The rating of the correlation between DRs.

\begin{tabular}{|c|c|c|c|c|c|c|c|c|c|c|c|c|c|c|c|}
\hline & \multicolumn{5}{|c|}{$E_{4}$} & \multicolumn{5}{|c|}{$E_{5}$} & \multicolumn{5}{|c|}{$E_{6}$} \\
\hline & $\mathrm{DR}_{1}$ & $\mathrm{DR}_{2}$ & $\mathrm{DR}_{3}$ & $\mathrm{DR}_{4}$ & $\mathrm{DR}_{5}$ & $\mathrm{DR}_{1}$ & $\mathrm{DR}_{2}$ & $\mathrm{DR}_{3}$ & $\mathrm{DR}_{4}$ & $\mathrm{DR}_{5}$ & $\mathrm{DR}_{1}$ & $\mathrm{DR}_{2}$ & $\mathrm{DR}_{3}$ & $\mathrm{DR}_{4}$ & $\mathrm{DR}_{5}$ \\
\hline $\mathrm{DR}_{1}$ & $\mathrm{DH}$ & $M$ & $\mathrm{H}$ & $\mathrm{L}$ & $\mathrm{VH}$ & $\mathrm{DH}$ & $\mathrm{L}$ & $\mathrm{H}$ & $\mathrm{VL}$ & $\mathrm{DH}$ & DH & $\mathrm{L}$ & $\mathrm{M}$ & $\mathrm{VL}$ & $\mathrm{VH}$ \\
\hline $\mathrm{DR}_{2}$ & & $\mathrm{DH}$ & $\mathrm{L}$ & $\mathrm{L}$ & $\mathrm{M}$ & & $\mathrm{DH}$ & $\mathrm{L}$ & $\mathrm{M}$ & $\mathrm{L}$ & & DH & $\mathrm{L}$ & $\mathrm{L}$ & $\mathrm{L}$ \\
\hline $\mathrm{DR}_{3}$ & & & $\mathrm{DH}$ & $\mathrm{M}$ & $\mathrm{H}$ & & & $\mathrm{DH}$ & $\mathrm{H}$ & $\mathrm{VH}$ & & & $\mathrm{DH}$ & $\mathrm{L}$ & $\mathrm{M}$ \\
\hline $\mathrm{DR}_{4}$ & & & & $\mathrm{DH}$ & $\mathrm{M}$ & & & & $\mathrm{DH}$ & $\mathrm{M}$ & & & & $\mathrm{DH}$ & $\mathrm{H}$ \\
\hline $\mathrm{DR}_{5}$ & & & & & $\mathrm{DH}$ & & & & & $\mathrm{DH}$ & & & & & DH \\
\hline
\end{tabular}

By solving this model, we obtain the weight vector of customer requirements:

$$
w=\{(\mathrm{DH},-0.33),(\mathrm{M}, 0.33),(\mathrm{VH}, 0.33),(\mathrm{DH}, 0),(\mathrm{M}, 0)\} .
$$

Then we can prioritize the CRs: $\mathrm{CR}_{4}>\mathrm{CR}_{1}>\mathrm{CR}_{3}>\mathrm{CR}_{2}$ $>\mathrm{CR}_{5}$. Thus, $\mathrm{CR}_{4}$ has the highest potential contribution to customer satisfaction and should be paid more attention during the following product development process. Moreover, the obtained weights are understandable because their values are in the form of linguistic terms instead of precise numbers.

Step 4. Calculate the collective correlation between DRs.

We transform linguistic decision matrixes in Table 2 into 2-tuple linguistic decision matrix and then derive the collective overall 2-tuple linguistic decision matrix, the results of which are shown in Table 5.

Step 5. Calculate the collective normalized relationship between CRs and DRs.

Firstly, we calculate the collective overall 2-tuple linguistic decision matrix based on the linguistic decision matrixes in Table 3 and the results are shown in Table 6.

Secondly, we use (17) to normalize the collective relationship between the CRs and DRs. For example, the normalized collective relationship between $\mathrm{CR}_{1}$ and $\mathrm{DR}_{1}$ can be calculated as

$$
\begin{aligned}
\mathrm{RL}_{11}^{\prime} & =\left(\mathrm{rl}_{11}^{\prime}, \varepsilon_{11}^{\prime}\right) \\
& =\frac{\sum_{h=1}^{5} \Delta^{-1}\left(\mathrm{rl}_{1 h}, \varepsilon_{1 h}\right) \times \Delta^{-1}\left(\mathrm{cl}_{h 1}, \epsilon_{h 1}\right)}{\sum_{j=1}^{5} \sum_{h=1}^{5} \Delta^{-1}\left(\mathrm{rl}_{1 h}, \varepsilon_{1 h}\right) \times \Delta^{-1}\left(\mathrm{cl}_{h j}, \epsilon_{h j}\right)} \\
& =\frac{76.78}{76.78+49.78+68.89+43.89+81.00} \\
& =0.24=(\mathrm{DL}, 0.24) .
\end{aligned}
$$

The normalized collective relationship between the CRs and DRs are shown in Table 7.
Step 6. Calculate the rating of the alternatives with respect to the DRs.

For example, the rating of $A_{1}$ with respect to $\mathrm{DR}_{1}$ can be calculated as

$$
\begin{aligned}
\left(r_{11}^{\prime}, \alpha_{11}^{\prime}\right)= & \Delta\left(\sum_{k=1}^{5} \Delta^{-1}\left(\mathrm{rl}_{k 1}^{\prime}, \varepsilon_{k 1}^{\prime}\right) \times \Delta^{-1}\left(r_{1 k}, \alpha_{1 k}\right)\right) \\
= & 5 \times 0.24+1.67 \times 0.21 \\
& +4.00 \times 0.20+5.33 \times 0.24 \\
& +2.00 \times 0.23 \\
= & 4.07=(\mathrm{H}, 0.07) .
\end{aligned}
$$

Based on ratings in Tables 4 and 7 , the rating of the alternatives with respect to the DRs is shown in Table 8.

Step 7. Calculate the weight of the DRs.

The weight of the DRs is the measure for DR on the overall impact of customer satisfaction. Based on the weight vector $w$ and normalized collective relationship in Table 7, the weight of DRs can be obtained by (19). The results are shown in Table 9.

Then we can prioritize the design requirements: $\mathrm{DR}_{5}>$ $\mathrm{DR}_{1}>\mathrm{DR}_{3}>\mathrm{DR}_{4}>\mathrm{DR}_{2}$. Thus, $\mathrm{DR}_{5}$ contributes more to the user satisfaction and more attention should be paid the $\mathrm{DR}_{5}$ in the development of products.

Step 8. Calculate the weighted rating of the alternatives with respect to the DRs.

By utilizing the weight vector in Table 9 and by (20), we can calculate the weighted rating of the alternatives. The calculated results of all the alternatives are shown in Table 10.

Step 9. Rank the alternatives. Rank the alternatives in ascending order of the total weighted ratings. The final ranking of the alternatives is

$$
A_{1}>A_{2}>A_{3}>A_{4}
$$


TABLE 3: The rating of the relationship between the CRs and DRs.

\begin{tabular}{cccccccccccccccc}
\hline & & & $E_{4}$ & & & & $E_{5}$ & & & & & & & \\
& $\mathrm{DR}_{1}$ & $\mathrm{DR}_{2}$ & $\mathrm{DR}_{3}$ & $\mathrm{DR}_{4}$ & $\mathrm{DR}_{5}$ & $\mathrm{DR}_{1}$ & $\mathrm{DR}_{2}$ & $\mathrm{DR}_{3}$ & $\mathrm{DR}_{4}$ & $\mathrm{DR}_{5}$ & $\mathrm{DR}_{1}$ & $\mathrm{DR}_{2}$ & $\mathrm{DR}_{3}$ & $\mathrm{DR}_{4}$ & $\mathrm{DR}_{5}$ \\
\hline $\mathrm{CR}_{1}$ & $\mathrm{DH}$ & $\mathrm{H}$ & $\mathrm{H}$ & $\mathrm{L}$ & $\mathrm{H}$ & $\mathrm{VH}$ & $\mathrm{M}$ & $\mathrm{M}$ & $\mathrm{L}$ & $\mathrm{H}$ & $\mathrm{VH}$ & $\mathrm{H}$ & $\mathrm{M}$ & $\mathrm{L}$ & $\mathrm{H}$ \\
$\mathrm{CR}_{2}$ & $\mathrm{M}$ & $\mathrm{DH}$ & $\mathrm{M}$ & $\mathrm{M}$ & $\mathrm{M}$ & $\mathrm{M}$ & $\mathrm{VH}$ & $\mathrm{H}$ & $\mathrm{M}$ & $\mathrm{M}$ & $\mathrm{H}$ & $\mathrm{VH}$ & $\mathrm{VH}$ & $\mathrm{M}$ & $\mathrm{M}$ \\
$\mathrm{CR}_{3}$ & $\mathrm{M}$ & $\mathrm{M}$ & $\mathrm{L}$ & $\mathrm{VH}$ & $\mathrm{M}$ & $\mathrm{L}$ & $\mathrm{L}$ & $\mathrm{VL}$ & $\mathrm{VH}$ & $\mathrm{H}$ & $\mathrm{M}$ & $\mathrm{H}$ & $\mathrm{VL}$ & $\mathrm{DH}$ & $\mathrm{H}$ \\
$\mathrm{CR}_{4}$ & $\mathrm{VH}$ & $\mathrm{H}$ & $\mathrm{M}$ & $\mathrm{L}$ & $\mathrm{DH}$ & $\mathrm{H}$ & $\mathrm{VL}$ & $\mathrm{M}$ & $\mathrm{L}$ & $\mathrm{VH}$ & $\mathrm{H}$ & $\mathrm{H}$ & $\mathrm{L}$ & $\mathrm{L}$ & $\mathrm{DH}$ \\
$\mathrm{CR}_{5}$ & $\mathrm{VH}$ & $\mathrm{L}$ & $\mathrm{DH}$ & $\mathrm{VH}$ & $\mathrm{H}$ & $\mathrm{VH}$ & $\mathrm{L}$ & $\mathrm{VH}$ & $\mathrm{H}$ & $\mathrm{M}$ & $\mathrm{DH}$ & $\mathrm{L}$ & $\mathrm{H}$ & $\mathrm{M}$ & $\mathrm{L}$ \\
\hline
\end{tabular}

TABLE 4: The collective rating of the alternatives given by the customers.

\begin{tabular}{cccccc}
\hline & $\mathrm{CR}_{1}$ & $\mathrm{CR}_{2}$ & $\mathrm{CR}_{3}$ & $\mathrm{CR}_{4}$ & $\mathrm{CR}_{5}$ \\
\hline$A_{1}$ & $(\mathrm{VH}, 0.00)$ & $(\mathrm{L},-0.33)$ & $(\mathrm{H}, 0.00)$ & $(\mathrm{VH}, 0.33)$ & $(\mathrm{L}, 0.00)$ \\
$A_{2}$ & $(\mathrm{H}, 0.00)$ & $(\mathrm{L}, 0.00)$ & $(\mathrm{M}, 0.33)$ & $(\mathrm{VH}, 0.33)$ & $(\mathrm{L}, 0.33)$ \\
$A_{3}$ & $(\mathrm{M}, 0.00)$ & $(\mathrm{VL}, 0.00)$ & $(\mathrm{M},-0.33)$ & $(\mathrm{H}, 0.00)$ & $(\mathrm{L}, 0.33)$ \\
$A_{4}$ & $(\mathrm{M}, 0.33)$ & $(\mathrm{L},-0.33)$ & $(\mathrm{L}, 0.33)$ & $(\mathrm{M}, 0.33)$ & $(\mathrm{VL}, 0.33)$ \\
\hline
\end{tabular}

TABLE 5: The collective rating of the correlation between DRs.

\begin{tabular}{lcccc}
\hline $\mathrm{DR}_{1}$ & $\mathrm{DR}_{2}$ & $\mathrm{DR}_{3}$ & $\mathrm{DR}_{4}$ & $\mathrm{DR}_{5}$ \\
\hline $\mathrm{DR}_{1}(\mathrm{DH}, 0.00)$ & $(\mathrm{L}, 0.33)$ & $(\mathrm{H},-0.33)$ & $(\mathrm{VL}, 0.33)$ & $(\mathrm{VH}, 0.33)$ \\
$\mathrm{DR}_{2}(\mathrm{VL}, 0.33)$ & $(\mathrm{DH}, 0.00)$ & $(\mathrm{L}, 0.00)$ & $(\mathrm{L}, 0.33)$ & $(\mathrm{L}, 0.33)$ \\
$\mathrm{DR}_{3}(\mathrm{H},-0.33)$ & $(\mathrm{L}, 0.00)$ & $(\mathrm{DH}, 0.00)$ & $(\mathrm{M}, 0.00)$ & $(\mathrm{H}, 0.00)$ \\
$\mathrm{DR}_{4}(\mathrm{VL}, 0.33)$ & $(\mathrm{L}, 0.33)$ & $(\mathrm{M}, 0.00)$ & $(\mathrm{DH}, 0.00)$ & $(\mathrm{M}, 0.33)$ \\
$\mathrm{DR}_{5}(\mathrm{VH}, 0.33)$ & $(\mathrm{L}, 0.33)$ & $(\mathrm{H}, 0.00)$ & $(\mathrm{M}, 0.33)$ & $(\mathrm{DH}, 0.00)$ \\
\hline
\end{tabular}

TABLE 6: The collective relationship between CRs and DRs.

\begin{tabular}{lcccc}
\hline $\mathrm{DR}_{1}$ & $\mathrm{DR}_{2}$ & $\mathrm{DR}_{3}$ & $\mathrm{DR}_{4}$ & $\mathrm{DR}_{5}$ \\
\hline $\mathrm{CR}_{1}(\mathrm{VH}, 0.33)$ & $(\mathrm{H},-0.33)$ & $(\mathrm{M}, 0.33)$ & $(\mathrm{L}, 0.00)$ & $(\mathrm{H}, 0.00)$ \\
$\mathrm{CR}_{2}(\mathrm{M}, 0.33)$ & $(\mathrm{VH}, 0.33)$ & $(\mathrm{H}, 0.00)$ & $(\mathrm{M}, 0.00)$ & $(\mathrm{M}, 0.00)$ \\
$\mathrm{CR}_{3}(\mathrm{M},-0.33)$ & $(\mathrm{M}, 0.00)$ & $(\mathrm{VL}, 0.33)$ & $(\mathrm{VH}, 0.33)$ & $(\mathrm{H},-0.33)$ \\
$\mathrm{CR}_{4}(\mathrm{H}, 0.33)$ & $(\mathrm{M}, 0.00)$ & $(\mathrm{M},-0.33)$ & $(\mathrm{L}, 0.00)$ & $(\mathrm{DH},-0.33)$ \\
$\mathrm{CR}_{5}(\mathrm{VH}, 0.33)$ & $(\mathrm{L}, 0.00)$ & $(\mathrm{VH}, 0.00)$ & $(\mathrm{H}, 0.00)$ & $(\mathrm{M}, 0.00)$ \\
\hline
\end{tabular}

TABLE 7: The normalized collective relationship between CRs and DRs.

\begin{tabular}{lccccc}
\hline & $\mathrm{DR}_{1}$ & $\mathrm{DR}_{2}$ & $\mathrm{DR}_{3}$ & $\mathrm{DR}_{4}$ & $\mathrm{DR}_{5}$ \\
\hline $\mathrm{CR}_{1}(\mathrm{DL}, 0.24)$ & $(\mathrm{DL}, 0.16)$ & $(\mathrm{DL}, 0.22)$ & $(\mathrm{DL}, 0.14)$ & $(\mathrm{DL}, 0.25)$ \\
$\mathrm{CR}_{2}(\mathrm{DL}, 0.21)$ & $(\mathrm{DL}, 0.18)$ & $(\mathrm{DL}, 0.21)$ & $(\mathrm{DL}, 0.16)$ & $(\mathrm{DL}, 0.23)$ \\
$\mathrm{CR}_{3}(\mathrm{DL}, 0.20)$ & $(\mathrm{DL}, 0.16)$ & $(\mathrm{DL}, 0.20)$ & $(\mathrm{DL}, 0.20)$ & $(\mathrm{DL}, 0.24)$ \\
$\mathrm{CR}_{4}(\mathrm{DL}, 0.24)$ & $(\mathrm{DL}, 0.15)$ & $(\mathrm{DL}, 0.21)$ & $(\mathrm{DL}, 0.14)$ & $(\mathrm{DL}, 0.26)$ \\
$\mathrm{CR}_{5}(\mathrm{DL}, 0.23)$ & $(\mathrm{DL}, 0.13)$ & $(\mathrm{DL}, 0.23)$ & $(\mathrm{DL}, 0.16)$ & $(\mathrm{DL}, 0.25)$ \\
\hline
\end{tabular}

From the ranking, clearly, we see that $A_{1}$ is the best design and it performs best with respect to all the DRs, while $A_{4}$ is considered as the worst and it performs worst with respect to all the DRs.

\section{Conclusions}

In this paper, we proposed the method for product design selection with incomplete linguistic weight information
TABLE 8: The rating of the alternatives with respect to the DRs.

\begin{tabular}{cccccc}
\hline & $\mathrm{DR}_{1}$ & $\mathrm{DR}_{2}$ & $\mathrm{DR}_{3}$ & $\mathrm{DR}_{4}$ & $\mathrm{DR}_{5}$ \\
\hline$A_{1}(\mathrm{H}, 0.07)$ & $(\mathrm{M},-0.2)$ & $(\mathrm{H},-0.2)$ & $(\mathrm{M},-0.15)$ & $(\mathrm{H}, 0.49)$ \\
$A_{2}(\mathrm{H},-0.16)$ & $(\mathrm{M},-0.36)$ & $(\mathrm{H},-0.4)$ & $(\mathrm{M},-0.31)$ & $(\mathrm{H}, 0.23)$ \\
$A_{3}(\mathrm{M},-0.06)$ & $(\mathrm{L},-0.01)$ & $(\mathrm{M},-0.24)$ & $(\mathrm{L}, 0.06)$ & $(\mathrm{M}, 0.24)$ \\
$A_{4}(\mathrm{M},-0.29)$ & $(\mathrm{L},-0.12)$ & $(\mathrm{M},-0.46)$ & $(\mathrm{L},-0.11)$ & $(\mathrm{M},-0.02)$ \\
\hline
\end{tabular}

TABLE 9: The weight of the DRs.

\begin{tabular}{lcccc}
\hline $\mathrm{DR}_{1}$ & $\mathrm{DR}_{2}$ & $\mathrm{DR}_{3}$ & $\mathrm{DR}_{4}$ & $\mathrm{DR}_{5}$ \\
\hline$(\mathrm{VH}, 0.22)$ & $(\mathrm{H},-0.34)$ & $(\mathrm{VH},-0.07)$ & $(\mathrm{H},-0.26)$ & $(\mathrm{DH},-0.22)$ \\
\hline
\end{tabular}

based on QFD in a fuzzy environment. The proposed method connects the customers' view and designers' view on the design and provides a more relaxing way to rate the weight of customer requirements. Firstly, we use the objective optimization model to calculate the weight of customer requirements based on the incomplete weight information given by group of customers. After the HoQ is constructed based on the linguistic assessment information given by group of designers, the opinions given by the customers are transformed into the opinions with respect to the design requirements. Then the priorities of the designs and design requirements are determined. The availability of the proposed method is validated by the numerical example.

The major advantages of the proposed method are as follows.

(i) The method facilitates the expression of the weight of the customer requirements. Customers are allowed to give incomplete linguistic weight information in four forms instead of precise linguistic terms.

(ii) The method not only facilities customers to express the preference with respect to the customer requirements but also makes the assessment results more understandable for designers because of the transformation of the customers' opinions into the opinions with respect to the design requirements based on the QFD.

(iii) The linguistic assessments information given by the customers and designers are processed more accurately by the 2 -tuple linguistic representation model. Since the 2-tuple linguistic representation model does not need the approximation process to express the result in the initial expression domain, it avoids the loss of information and the lack of precision. 
TABLE 10: The weighted rating of the alternatives with respect to the DRs.

\begin{tabular}{|c|c|c|c|c|c|c|}
\hline & $\mathrm{DR}_{1}$ & $\mathrm{DR}_{2}$ & $\mathrm{DR}_{3}$ & $\mathrm{DR}_{4}$ & $\mathrm{DR}_{5}$ & Total \\
\hline$A_{1}$ & $(\mathrm{VL},-0.09)$ & (DL, 0.44) & $(\mathrm{VL},-0.2)$ & (DL, 0.46) & (VL, 0.11) & $(\mathrm{H},-0.28)$ \\
\hline$A_{2}$ & $(\mathrm{VL},-0.14)$ & $(\mathrm{DL}, 0.41)$ & $(\mathrm{VL},-0.24)$ & $(\mathrm{DL}, 0.43)$ & $(\mathrm{VL}, 0.05)$ & $(\mathrm{H},-0.49)$ \\
\hline$A_{3}$ & $(\mathrm{VL},-0.34)$ & $(\mathrm{DL}, 0.31)$ & $(\mathrm{VL},-0.42)$ & $(\mathrm{DL}, 0.33)$ & $(\mathrm{VL},-0.20)$ & $(\mathrm{M},-0.31)$ \\
\hline$A_{4}$ & $(\mathrm{VL},-0.39)$ & $(\mathrm{DL}, 0.29)$ & $(\mathrm{VL},-0.46)$ & $(\mathrm{DL}, 0.30)$ & $(\mathrm{VL},-0.26)$ & $(\mathrm{L},-0.48)$ \\
\hline
\end{tabular}

\section{Acknowledgments}

This research is supported by the National Natural Science Foundation of China under Grant no. 71101153 and the Research Funds Provided to New Recruitments of China University of Petroleum, Beijing (QD-2010-06).

\section{References}

[1] G. Boothroyd, "Product design for manufacture and assembly," Computer-Aided Design, vol. 26, no. 7, pp. 505-520, 1994.

[2] G. Barczak and K. B. Kahn, "Identifying new product development best practice," Business Horizons, vol. 55, no. 3, pp. 293305, 2012.

[3] A. C. Oliveira and P. C. Kaminski, "A reference model to determine the degree of maturity in the product development process of industrial SMEs," Technovation, vol. 32, no. 12, pp. 671-680, 2012.

[4] K. B. Kahn, G. Barczak, and J. Nicholas, "An examination of new product development best practice," Journal of Product Innovation Management, vol. 29, no. 2, pp. 180-192, 2012.

[5] S. Land, A. Engelen, and M. Brettel, “Top management's social capital and learning in new product development and its interaction with external uncertainties," Industrial Marketing Management, vol. 41, no. 3, pp. 521-530, 2011.

[6] D. Kandemir and N. Acur, "Examining proactive strategic decision-making flexibility in new product development," Journal of Product Innovation Management, vol. 29, no. 4, pp. 608622, 2012.

[7] Y. Akao, Quality Function Deployment: Integrating Customer Requirements Into Product Design, Productivity Press, Cambridge, Mass, USA, 1990.

[8] J. R. Hauser and C. Don, "The house of quality," Harvard Business Review, vol. 66, no. 5-6, pp. 63-73, 1988.

[9] S. B. Han, S. K. Chen, M. Ebrahimpour, and M. S. Sodhi, "A conceptual QFD planning model," International Journal of Quality and Reliability Management, vol. 18, no. 8, pp. 796-812, 2001.

[10] Y. Chen, J. Tang, R. Y. K. Fung, and Z. Ren, "Fuzzy regressionbased mathematical programming model for quality function deployment," International Journal of Production Research, vol. 42, no. 5, pp. 1009-1027, 2004.

[11] K. J. Kim, H. Moskowitz, A. Dhingra, and G. Evans, "Fuzzy multicriteria models for quality function deployment," European Journal of Operational Research, vol. 121, no. 3, pp. 504-518, 2000.

[12] X. T. Wang and W. Xiong, "An integrated linguistic-based group decision-making approach for quality function deployment," Expert Systems With Applications, vol. 38, no. 12, pp. 1442814438, 2011.
[13] L. Martínez, D. Ruan, and F. Herrera, "Computing with words in decision support systems: an overview on models and applications," International Journal of Computational Intelligence Systems, vol. 3, no. 4, pp. 382-395, 2010.

[14] L. A. Zadeh, "A computational approach to fuzzy quantifiers in natural languages," Computers \& Mathematics with Applications, vol. 9, no. 1, pp. 149-184, 1983.

[15] M. Li, "The extension of quality function deployment based on 2-tuple linguistic representation model for product design under multi-granularity linguistic environment," Mathematical Problems in Engineering, vol. 2012, Article ID 989284, 18 pages, 2012.

[16] M. Li, L. Liu, and C. B. Li, "An approach to expert recommendation based on fuzzy linguistic method and fuzzy text classification in knowledge management systems," Expert Systems with Applications, vol. 38, no. 7, pp. 8586-8596, 2011.

[17] R. M. Rodríguez and L. Martínez, "An analysis of symbolic linguistic computing models in decision making," International Journal of General Systems, vol. 42, no. 1, pp. 121-136, 2013.

[18] J. M. Mendel, L. A. Zadeh, E. Trillas et al., "What computing with words means to me," IEEE Computational Intelligence Magazine, vol. 5, no. 1, pp. 20-26, 2010.

[19] R. M. Rodríguez, L. Martínez, and F. Herrera, "Hesitant fuzzy linguistic term sets for decision making," IEEE Transactions on Fuzzy Systems, vol. 20, no. 1, pp. 109-119, 2012.

[20] O. Martin and G. J. Klir, "On the problem of retranslation in computing with perceptions," International Journal of General Systems, vol. 35, no. 6, pp. 655-674, 2006.

[21] R. R. Yager, "A new methodology for ordinal multi-objective decisions based on fuzzy sets," Decision Sciences, vol.12, pp. 589600, 1981.

[22] R. Heradio, D. Fernández-Amorós, F. J. Cabrerizo, and E. Herrera-Viedma, "A review of quality evaluation of digital libraries based on users' perceptions," Journal of Information Science, vol. 38, no. 3, pp. 269-283, 2012.

[23] F. Herrera, E. Herrera-Viedma, and L. Martínez, "A fuzzy linguistic methodology to deal with unbalanced linguistic term sets," IEEE Transactions on Fuzzy Systems, vol. 16, no. 2, pp. 354$370,2008$.

[24] F. Herrera and E. Herrera-Viedma, "Linguistic decision analysis: steps for solving decision problems under linguistic information," Fuzzy Sets and Systems, vol. 115, no. 1, pp. 67-82, 2000.

[25] F. Mata, L. Martínez, and E. Herrera-Viedma, "An adaptive consensus support model for group decision-making problems in a multigranular fuzzy linguistic context," IEEE Transactions on Fuzzy Systems, vol. 17, no. 2, pp. 279-290, 2009.

[26] F. Herrera and L. Martínez, "A 2-tuple fuzzy linguistic representation model for computing with words," IEEE Transactions on Fuzzy Systems, vol. 8, no. 6, pp. 746-752, 2000.

[27] Z. Xu, "A method based on linguistic aggregation operators for group decision making with linguistic preference relations," Information Sciences, vol. 166, no. 1, pp. 19-30, 2004. 
[28] J. H. Wang and J. Hao, "A new version of 2-tuple fuzzy linguistic representation model for computing with words," IEEE Transactions on Fuzzy Systems, vol. 14, no. 3, pp. 435-445, 2006.

[29] L. Martínez and F. Herrera, "An overview on the 2-tuple linguistic model for computing with words in decision making: extensions, applications and challenges," Information Sciences, vol. 207, pp. 1-18, 2012.

[30] E. Herrera-Viedma, G. Pasi, A. G. Lopez-Herrera, and C. Porcel, "Evaluating the information quality of Web sites: a methodology based on fuzzy computing with words," Journal of the American Society for Information Science and Technology, vol. 57, no. 4, pp. 538-549, 2006.

[31] R. A. Carrasco, P. Villar, M. Hornos, and E. Herrera-Viedma, "A linguistic multi-criteria decision making model applied to hotel service quality evaluation from web data sources," International Journal of Intelligent Systems, vol. 27, no. 7, pp. 704-731, 2012.

[32] J. M. Moreno, J. M. Morales del Castillo, C. Porcel, and E. Herrera-Viedma, "A quality evaluation methodology for healthrelated websites based on a 2-tuple fuzzy linguistic approach," Soft Computing, vol. 14, no. 8, pp. 887-897, 2010.

[33] E. Herrera-Viedma, E. Peis, J. M. Morales-del-Castillo, S. Alonso, and K. Anaya, "A fuzzy linguistic model to evaluate the quality of Web sites that store XML documents," International Journal of Approximate Reasoning, vol. 46, no. 1, pp. 226-253, 2007.

[34] K. S. Park, S. H. Kim, and W. C. Yoon, "Establishing strict dominance between alternatives with special type of incomplete information," European Journal of Operational Research, vol. 96, no. 2, pp. 398-406, 1997.

[35] S. H. Kim, S. H. Choi, and J. K. Kim, "Interactive procedure for multiple attribute group decision making with incomplete information: range-based approach," European Journal of Operational Research, vol. 118, no. 1, pp. 139-152, 1999.

[36] C. Porcel and E. Herrera-Viedma, "Dealing with incomplete information in a fuzzy linguistic recommender system to disseminate information in university digital libraries," KnowledgeBased Systems, vol. 23, no. 1, pp. 32-39, 2010.

[37] S. Alonso, F. J. Cabrerizo, F. Chiclana, F. Herrera, and E. Herrera-Viedma, "Group decision making with incomplete fuzzy linguistic preference relations," International Journal of Intelligent Systems, vol. 24, no. 2, pp. 201-222, 2009.

[38] E. Herrera-Viedma, S. Alonso, F. Chiclana, and F. Herrera, "A consensus model for group decision making with incomplete fuzzy preference relations," IEEE Transactions on Fuzzy Systems, vol. 15, no. 5, pp. 863-877, 2007.

[39] E. Herrera-Viedma, F. Chiclana, F. Herrera, and S. Alonso, "Group decision-making model with incomplete fuzzy preference relations based on additive consistency," IEEE Transactions on Systems, Man, and Cybernetics B, vol. 37, no. 1, pp. 176-189, 2007.

[40] P. S. Park and S. H. Kim, "Tools for interactive multi-attribute decision making with incompletely identified information," European Journal of Operational Research, vol. 98, no. 1, pp. 111123, 1997.

[41] $\mathrm{Z}$. $\mathrm{Xu}$, "A method for multiple attribute decision making with incomplete weight information in linguistic setting," Knowledge-Based Systems, vol. 20, no. 8, pp. 719-725, 2007.

[42] G. W. Wei, "GRA method for multiple attribute decision making with incomplete weight information in intuitionistic fuzzy setting," Knowledge-Based Systems, vol. 23, no. 3, pp. 243-247, 2010.
[43] G. W. Wei, "Grey relational analysis method for 2-tuple linguistic multiple attribute group decision making with incomplete weight information," Expert Systems with Applications, vol. 38, no. 5, pp. 4824-4828, 2011.

[44] G. W. Wei, "Extension of TOPSIS method for 2-tuple linguistic multiple attribute group decision making with incomplete weight information," Knowledge and Information Systems, vol. 25, no. 3, pp. 623-634, 2010.

[45] Z. Xu, "An interactive procedure for linguistic multiple attribute decision making with incomplete weight information," Fuzzy Optimization and Decision Making, vol. 6, no. 1, pp. 17-27, 2007.

[46] S. H. Kim and B. S. Ahn, "Interactive group decision making procedure under incomplete information," European Journal of Operational Research, vol. 116, no. 3, pp. 498-507, 1999.

[47] L. Lam and C. Y. Suen, "Application of majority voting to pattern recognition: an analysis of its behavior and performance," IEEE Transactions on Systems, Man, and Cybernetics A, vol. 27, no. 5, pp. 553-568, 1997.

[48] D. Ruta and B. Gabrys, "Classifier selection for majority voting," Information Fusion, vol. 6, no. 1, pp. 63-81, 2005.

[49] H. Yamashina, T. Ito, and H. Kawada, "Innovative product development process by integrating QFD and TRIZ," International Journal of Production Research, vol. 40, no. 5, pp. 10311050, 2002. 


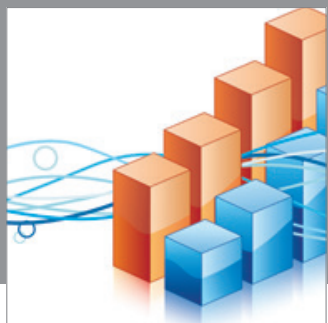

Advances in

Operations Research

mansans

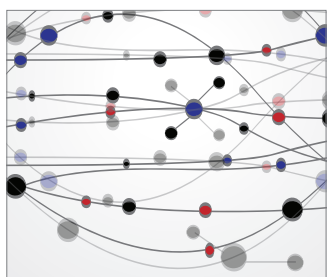

The Scientific World Journal
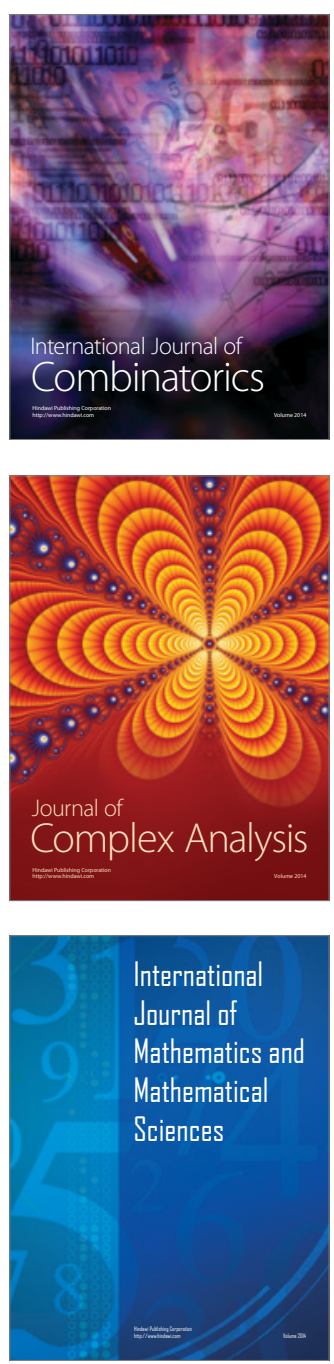
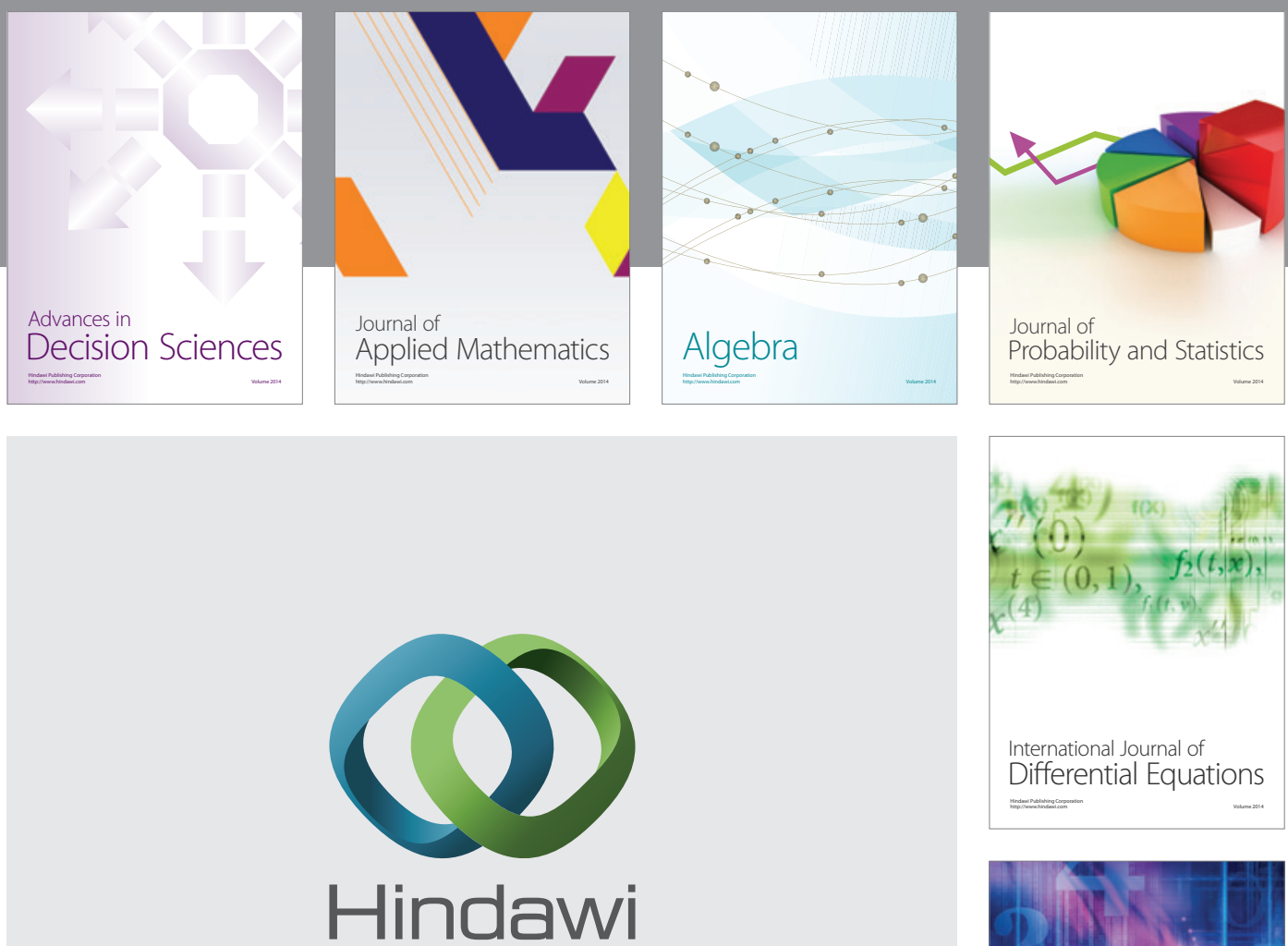

Submit your manuscripts at http://www.hindawi.com
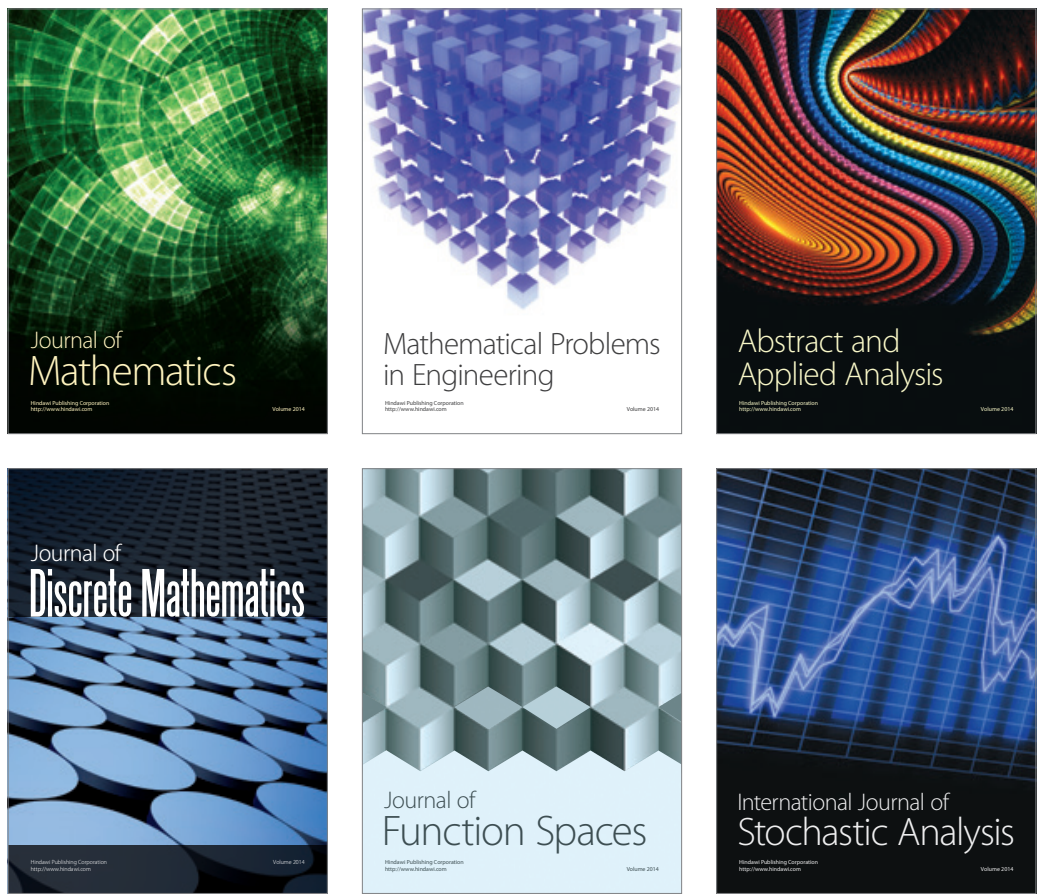

Journal of

Function Spaces

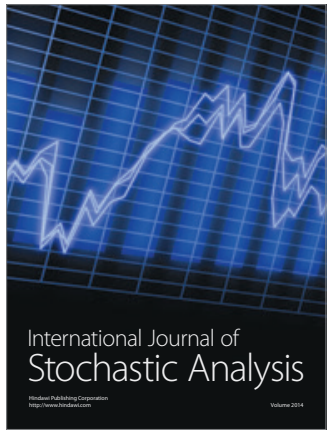

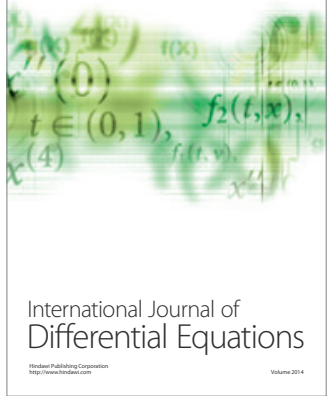
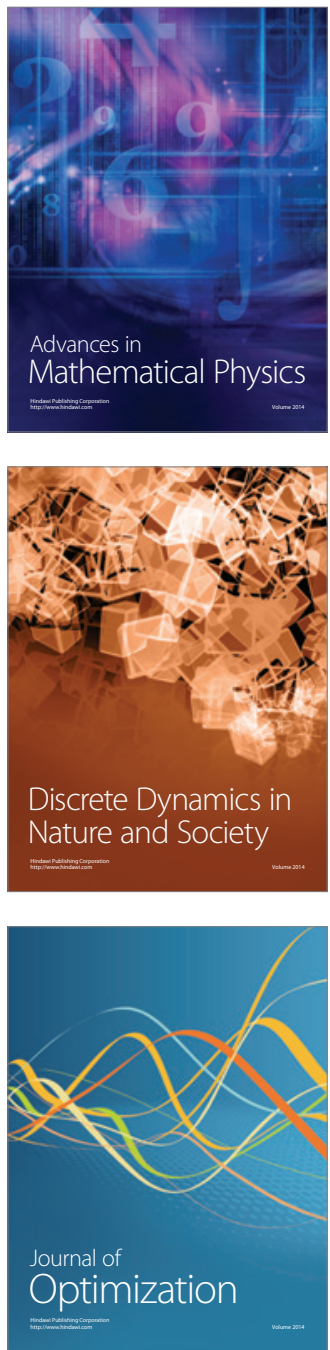